\section{Prazer e Religião em Nelson Rodrigues}

\section{Pleasure and Religion in Nelson Rodrigues}

\section{Resumo}

Este ensaio apresenta uma análise da obra de Nelson Rodrigues sob o enfoque de um tema: Prazer e Religião. Nelson Rodrigues é considerado um dos ícones do teatro brasileiro e fundador do expressionismo como linguagem teatral no Brasil. Entender Nelson Rodrigues e sua obra passa pelo entendimento dos fatores constitutivos de sua vida, formação religiosa, opção pelo expressionismo, seus dramas pessoais e sua criatividade literária. O prazer em Nelson Rodrigues torna-se uma religião na medida em que celebra a vida, e a religião é a própria vida na medida de seus temas recorrentes.

Palavras-chave: Prazer, Religião, Nelson Rodrigues, Expressionismo, Vida e Morte.

\section{Abstract}

This essay presents an analysis of Nelson Rodrigues work under the focus of a theme: Pleasure and Religion. Nelson Rodrigues is considered one of Brazilian theater icons and the founder of expressionism as a theatrical language in Brazil. Understanding Nelson Rodrigues and his work involves the understanding of the constitutive factors of his life, religious formation, expressionism choice, his personal dramas and literary creativity. Nelson Rodrigues's pleasure becomes a religion insofar as it celebrates life, and religion is life itself to the extent of its recurring themes.

\section{Introdução}

Este ensaio procurará analisar a obra de Nelson Rodrigues como um esforço de interpretação a partir do tema prazer e religião. Em que pese à hermenêutica do ser envolvida no trabalho do cientista da religião, analisar Nelson é mergulhar em um universo mítico que traduz o mais profundo do ser em sua angústia de prazer/religião, vida/morte. Nisso está o ponto de intersecção entre Nelson e a religião: na celebração da vida que se morre, na celebração da morte que se vive.
Prof. Dr. Élton de

Oliveira Nunes

É pós-doutor em Ciências das Religiões pela Pontifícia Universidade Católica de São Paulo (PUC-SP), mestre e doutor em Ciências da Religião pela Universidade Metodista (UMESP).

E-mail: eltononunes@ gmail.com 
Para entender a obra desse autor, investigamos as seguintes linhas: a formação religiosa de Nelson Rodrigues como campo de entendimento do pano de fundo de suas ideias; a criatividade literária como forma de expressão original e própria; e o enquadramento teórico de sua obra dentro da linha filosófica e teatral como o modo de entendimento geral. Essas linhas nos levaram a adotar os princípios gerais da psicanálise de orientação freudiana como referencial teórico. Esse caminho, já trilhado por outros (vide, Carmine Martuscello, Maria Albuquerque, Valderez Cardoso Gomes, Ronaldo Lima Lins, entre outros), proporcionou a compreensão geral e uma ferramenta hermenêutica para uma interpretação da obra de Nelson Rodrigues.

Na primeira parte, abordaremos de forma resumida os principais pontos biográficos de Nelson Rodrigues (Síntese da vida e obra de Nelson Rodrigues). Na segunda, trataremos do referencial teórico para abordagem do tema em Nelson Rodrigues (Por uma escolha referencial metodológica). Na terceira parte, apresentaremos uma leitura do sobre prazer e religião em Nelson Rodrigues a partir do referencial teórico adotado (Prazer e religião em Nelson Rodrigues). Por fim, apresentamos nossas conclusões sobre o tema e as referências bibliográficas.

\section{Síntese da vida e obra de Nelson Rodrigues}

Nelson Falcão Rodrigues nasceu no Recife, em 23 de agosto de 1912, o quinto filho de uma família de catorze. Quando tinha três anos, seu pai, Mário Rodrigues, foi tentar a sorte no Rio de Janeiro. O acordo feito com a esposa era que tão logo encontrasse trabalho, chamaria a família ao seu encontro. Maria Esther, sua esposa, não aguentou esperar. Em 1916, empenhou as joias e mandou um telegrama para o marido, já avisando do embarque naquele mesmo dia.

O primeiro endereço da Família Rodrigues no Rio de Janeiro foi a Rua Alegre, na Aldeia Campista. Durante esse período, Nelson começou a desenvolver sua apurada observação sobre o mundo e entrou em contato com o universo passional que seria tema de suas obras, como a lembrança do rapaz que tomou veneno, em 1917, por ter brigado com sua namorada, e da imagem da mãe e da namorada do morto disputando o defunto em pleno velório.

No Rio, seu pai fundou o jornal A Manhã, onde Nelson começou sua carreira jornalística. Em 1929, tendo perdido o A Manhã, Mário Rodrigues lança o jornal Crítica. Esse será palco da primeira grande tragédia que acometerá a família: o assassinato de Roberto. O fato ocorreu por conta de uma reportagem acusatória. O Crítica ia publicar "as causas ocultas" do divórcio de uma mulher da sociedade, o motivo não alegado publicamente seria o adultério. Quando soube que a matéria sairia no jornal, Sylvia Seraphim foi até a redação para tomar satisfações. A moça entrou na redação do jornal, no dia 26 de dezembro, e perguntou: "O Mário Rodrigues está?". Como ele não se encontrava, perguntaram se ela poderia falar com o filho dele, Roberto, o que ela aceitou. Roberto recebeu a moça e fechou a porta da sala, foi o tempo necessário para ela sacar o revólver de dentro da bolsa e atirar.

O assassinato de Roberto marcou profundamente a trajetória da família. Mário Rodrigues, inconformado por seu filho ter sido morto em seu lugar, passou a exagerar na bebida e, em pouco mais de dois meses, morreu. Passados poucos meses, o Critíca foi fechado pela polícia, por ordens do governo, com a vitória de Getúlio Vargas, na Revolução de 1930. Começou, assim, o período da fome, que duro até 1935, quando a situação começou a melhorar; os Rodrigues experimentaram a miséria. $O$ saldo do período foi as duas tuberculoses de Nelson, que chegou a ser internado, e a morte de Joffre, aos 21 anos, também devido à tuberculose - Joffre era o irmão mais próximo de Nelson, ele dizia que era como se os dois fossem gêmeos.

A partir de 1936, ano da morte de Joffre, Nelson começou a colaborar com diversos veículos, como o Correio da Manhã, O Jornal, Última Hora, 
Jornal dos Sports, Manchete Esportiva e Jornal do Brasil, entre outros. Escreverá crônicas, contos, correio sentimental, folhetins, comentário esportivo e artigos opinativos. O teatro surge em 1941, quando estreia A Mulher Sem Pecado, texto pelo qual Nelson foi muito aclamado; contudo, será com a encenação de Vestido de Noiva, dirigida por Ziembinski, que se tornará marco do teatro brasileiro moderno.

Com uma capacidade de trabalho invejável, Nelson ainda fez história na televisão brasileira. Participou de mesas-redondas, foi pioneiro na teledramaturgia brasileira ao escrever, para a TV Rio, a novela A Morta Sem Espelho. Em vida, acompanhou a adaptação de sua obra para o cinema e chegou a colaborar com o roteiro de A Dama do Lotação, de Neville D Almeida, Bonitinha, mas ordinária e Álbum de Família, de Braz Chediak. Escreveu também os diálogos para dois filmes: Somos Dois, de Milton Rodrigues; e Como ganhar na loteria sem perder a esportiva, de J. B. Tanko.

No final da vida, Nelson estava bastante debilitado e sofria muito. Depois de um aneurisma na aorta, foi operado três vezes. Seu estado era agravado pelo fato de nunca ter tido uma saúde equilibrada. Nelson Rodrigues morreu no dia 21 de dezembro de 1980, deixando seis filhos: Jofre, Nelson, Maria Lucia, Paulo César, Sonia e Daniela.

A obra de Nelson Rodrigues é classificada dentro da linha filosófica e teatral denominada de expressionismo que se caracteriza por expressar fortes sentimentos e os conflitos deles resultantes. Como nos traz Elizabeth Luckesi,

O expressionismo é um movimento artístico que se caracteriza pela expressão de intensas emoções. As obras não têm preocupação com o padrão de beleza tradicional e exibem enfoque pessimista da vida, marcado pelos fortes sentimentos humanos. O prazer, a angústia, a dor, são os temas mais abordados. (LUCKESI, 2001, p. 3)
Iniciado no fim do século XIX por artistas plásticos da Alemanha, o expressionismo alcança seu auge entre 1910 e 1920 e expande-se para a literatura, a música, o teatro e o cinema. Em função da I Guerra Mundial e das limitações impostas pela língua alemã, tem maior expressão entre os povos germânico, eslavo e nórdico. Após o fim da guerra, influencia a arte em outras partes do mundo. Muitos artistas estão ligados a grupos políticos de esquerda. Assim como a Revolução Russa (1917), as teorias psicanalíticas do austríaco Sigmund Freud, a evolução da ciência e a filosofia do alemão Friedrich Nietzsche, o expressionismo está inserido no ambiente conturbado que marca a virada do século. No Brasil, o expressionismo marcou as artes no início do século $X X$ e representa importante etapa das artes e da literatura.

A obra de Nelson Rodrigues revolucionou de tal forma a dramartugia brasileira que podemos denominá-lo como um divisor de águas. Com suas técnicas inusitadas de corte de cenas e ritmos, o dramaturgo inaugurou o expressionismo no moderno teatro brasileiro. Suas obras podem ser divididas em três grupos temáticos:

- Obras psicológicas, em que se destacam os problemas do homem enquanto homem e enquanto membro de uma sociedade hipócrita que o criou e que é deformada por ele;

- Obras míticas, cujo enredo sempre gira em torno dos instintos humanos, da busca pelas raízes dessas ações e sentimentos;

- Tragédias, em que o mundo moderno aparece para ser desmascarado, com toda a seu egoísmo, mesquinhez e futilidade.

\section{Por uma escolha referencial metodológica}

Como observamos, analisar Nelson Rodrigues é um esforço hermenêutico. Como proceder no entendimento de sua obra? Como avançar em relação ao tema proposto: religião e prazer? Fraga já se debate com isso ao afirmar que: 
Não fosse Nelson Rodrigues um dramaturgo naturalmente polêmico, os pontos de vista contraditórios sobre a sua obra se tornariam estranháveis. Caberia encontrar um denominador comum, que não se confunde com a unanimidade de apreço que hoje em dia the votam. Refiro-me à hermenêutica em si dos textos e seu correspondente juízo de valor. Nesse campo, as possíveis diferenças não se espantam. (FRAGA, 1998, p. 14)

Em nossa compreensão, para podermos apresentar uma possivel interpretação sobre a obra de Nelson Rodrigues e sua perspectiva em relação à religião e ao prazer, é necessário elencar os pontos fundamentais que caracterizam sua vida. Quatro são os elementos que consideramos importantes: sua história de vida, sua criatividade dramática, sua opção pelo expressionismo e, principalmente, a formação cristã de infância. Esses elementos estão entrelaçados de tal forma na obra rodrigueana que essa se confunde em cada um deles, como podemos atestar em relação à sua formação religiosa. Francisco Carneiro da Cunha, um dos dramaturgos que se especializou na obra de Nelson Rodrigues, diz que há em Nelson Rodrigues um forte sentido religioso e mítico,

Depois da publicação de "O anjo pornográfico" em 1992, sua biografia escrita por Ruy Castro, e da publicação de todas as suas crônicas nos anos seguintes, ninguém mais pode duvidar da importância do drama da Paixão na formação do poeta que nasceu e cresceu num forte ambiente religioso. Sua mãe foi batista praticante e - pai obrigado a fazer-se pastor (batista) para casar, ao passo que suas tias católicas e protestantes o doutrinavam sem cessar e por isso aparecem em suas pecas como pacas. (CUNHA, 2000, p. 13)

A religião, como conjunto de crenças e atitudes de negação de si e exaltação do outro maior que si-mesmo, faz parte da obra de Nelson Rodrigues. Nas palavras de Francisco Carneiro da Cunha,
Aos dez anos, Nélson Rodrigues já escrevia a estória de uma adúltera (Madalena) assassinada pelo marido (Jesus) que, em seguida, ajoelhado e contrito, pede perdão à morta enquanto o amante (Satanás) foge na escuridão da noite. Redação que the deu o primeiro lugar na classe deixando boquiabertas sua professora e sua mãe e na qual já estão presentes todos os arquétipos evangélicos de seus futuros dramas. (CUNHA, 2000, p. 13)

Outro componente importante para entendermos Nelson Rodrigues está na história de vida do autor. Comentando o absurdo da vida de Nelson, Sábato Malgadi nos diz que:

O dramaturgo não esconde que o sentimento de pessimismo e absurdo se fincou nele a partir do assassínio do irmão, excelente desenhista, Roberto Rodrigues. Uma mulher entrou na redação do jornal de propriedade de seu pai, Mário Rodrigues, perguntando por ele. Na ausência, ela falaria com qualquer filho. Introduzida a Roberto, matou-o a tiros, como poderia ter feito com o próprio Nelson. Não importam as razões que determinaram a criminosa a despejar no filho a ira contra o pai. $O$ ato em si, carregado de absurdo, sublinhando o efêmero de qualquer projeto de vida. Mário, apaixonado pela morte de Roberto, sobreviveu-lhe dois meses. Esses episódios, semelhantes ao arbítrio implacável do destino, na tragédia grega, dariam o substrato do escuro pensamento do escritor. No julgamento da criminosa, mobilizou-se a favor dela a opinião pública. Absolveu-a o veredicto do júri, (para Nelson) tornaram-se culpados todos os que justificaram o assassínio. (MAGALDI, 1992, p. 68).

Por esta razão, elencamos aqui os elementos constitutivos para o pré-entendimento de Nelson Rodrigues:

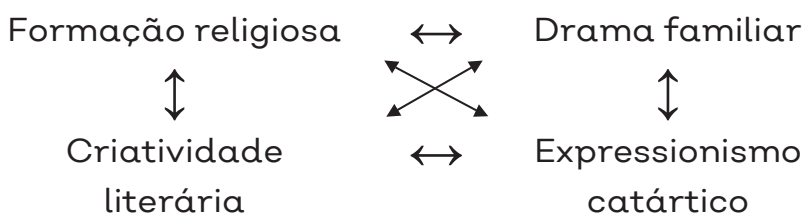


Esses elementos têm forte apelo psicológico e necessitam ser examinados por esse prisma.

Concorda com isso Albuquerque (2001, p. 01) quando diz que:

\begin{abstract}
A Psicanálise tornou clara a idéia de que a repressão dos anseios mais primitivos do homem surgiu decorrente das regras do jogo social. Em Totem e Tabu (19121913), Freud refere-se justamente a essa questão do controle social dos impulsos, concluindo que o homem nunca internaliza completamente a interdição. Daí consiste na necessidade de o grupo social criar um sistema interno que garanta sua ordem interna, decorrendo disso - conflito de duas grandes forças que são o desejo de violação das normas instituídas e o recalque do desejo por uma questão de imposição social. O estudo deveu-se ao interesse de Freud pela Antropologia, assim como pela inter-relação entre a civilização e a repressão dos instintos. Em Álbum de Família, emerge os recônditos impulsos da natureza humana, dentre eles o incestuoso. Nélson Rodrigues não se afasta de um cunho moralizador, ao contrário do que possa aparentar uma visão superficial equivocada. (ALBUQUERQUE, 2001, p. 01)
\end{abstract}

A psicanálise, de orientação freudiana, apresenta o princípio de vida (que tem sua base primordial nos desejos sexuais) e a sua rejeição pela sociedade (consciente e inconsciente). O homem, nesse contexto, é sempre um ser em conflito com o seu meio social e suas demandas. O conflito é a marca do teatro e da obra rodriguiana. Além disso, Sábato Magaldi ainda apontar que essa era a atmosfera da obra de Nelson Rodrigues, na medida em que o mesmo usa:

Os três planos do texto - realidade, memória e alucinação - privilegiaram o subconsciente da heroína, novidade num teatro que ainda se movimentava na psicologia tradicional. A Mulher Sem Pecado (1941), que lançou o autor, já estava prestes a romper a censura do consciente. Se Vestido de Noiva é a projeção exterior da mente da protagonista, o monólogo Valsa $n^{\circ} 6$ (1951) incorpora o mundo exterior ao desempenho da heroína, que encarna em cena as personagens de seu convívio. (MAGALDI, 1979, p. 01)

A irracionalidade comanda os atos das personagens de Nelson, movidas pelo desejo desenfreado e autodestrutivo.

\section{Prazer e Religião em Nelson Rodrigues}

Nelson Rodrigues retrata sua obra com um mesmo tema recorrente. Para ele, era como uma pregação de um tema só. Eudinyr Fraga, comentando a obra de Nelson, diz:

\begin{abstract}
Nelson chamava a si próprio de flor de obsessão, expressão que se repetiu em livros, ensaios e artigos sobre ele, mas que poderia ser aplicada, da mesma forma, à análise da produção artística de um sem-número de pessoas, sem querer afirmar que todas trabalham, da mesma forma, o mesmo material. Poderíamos denominar o fenômeno de unidade de pensamento. (FRAGA, 1998, p. 49)
\end{abstract}

Essa unidade de pensamento em Nelson é determinada por uma recorrência religiosa, como nos atesta Sábato Magaldi (1992, p. 21): "Nelson gostava de repetir que seu teatro era uma meditação sobre o amor e sobre a morte". Esse amor era a própria vida, a qual vivia em uma intensidade alucinante. Essa vida que se desfaz na morte está presente em todas as suas peças. Para uma noção desse tema recorrente, elencamos algumas das peças de Nelson: 
Tabela 1

\begin{tabular}{|l|l|}
\multicolumn{1}{|c|}{ Peça } & \multicolumn{1}{c|}{ Tipo de violência } \\
\hline A mulher sem pecado & Morte \\
\hline Vestido de noiva & Suicídio \\
\hline Álbum de família & Assassinatos \\
\hline Senhora dos afogados & Mortes e assassinatos \\
\hline Dorotéia & Estrangulamentos \\
\hline A falecida & Morte \\
\hline Perdoa-me por me traíres & Morte \\
\hline
\end{tabular}

A morte é natural como a vida, ela é o fim da vida, mas também libertação da mesma. Para Nelson, não pode haver vida sem essa ser uma trajetória obrigatória para a morte. Esse é um dos temas recorrentes de Nelson, como nos atesta ainda Sábato Magaldi (1992, p. 79): "Nelson vê no dilaceramento humano o caos, a desordem, a morte. Por isso a maioria de suas peças desfila assassínios e suicídios".

Mas que vida é essa que leva para a morte? E por que mortes violentas e, em um sentido, punitivas e autopunitivas? Podemos buscar uma resposta no drama cristão de sentido e negação, mais precisamente na fórmula cristã do sofrimento para a redenção: desejo, pecado, punição (Cf. uma leitura pietista de Tg. 1:13-15). Magaldi (1992, p. 30) vê claramente isso quando comenta: "A falta de autoestima não transparece apenas nos atos extremos do suicídio. A cada momento, uma personagem necessita de punição".

A nós, torna-se claro aqui que Nelson revive em suas tramas o calvário do ser humano no drama da vida cristã. Ao desejar, comete o ser humano pecado. Ao pecar, vem a punição. Mas, em Nelson, a punição é também uma forma de redenção. Ao ser punido, de alguma forma, o ser se redime. Essa redenção, contudo, não termina, pois novo ciclo de desejo irrompe e o drama recomeça. Por isso, novamente a peça se reinicia com outros nomes e situações, mas sempre o mesmo drama. Falando sobre isso, Francisco Carneiro da Cunha, citando Nelson Rodrigues, afirma:
A ficção para ser purificadora tem de ser atroz. O personagem é vil para que não o sejamos. Ele realiza a miséria inconfessa de cada um de nós. E no teatro que é mais plástico, direto e de um impacto tão mais puro esse fenômeno de transparência torna-se mais válido. Para salvar a platéia é preciso encher o palco de assassinos, adúlteros e insanos, em suma, de uma rajada de monstros. São os nossos monstros íntimos dos quais eventualmente nos libertamos para em seguida recriá-los em cena novamente. (CUNHA, 2001, p. 15)

O drama de Nelson é o drama cristão. Nelson busca a redenção, pois vida é desejo (sexual) e desejo é intolerável na sociedade (expressa na família cristã-burguesa). O outro é objeto sempre proibido. Magaldi comenta:

Tendo recebido a formação cristã de classe média urbana brasileira, o dramaturgo preservou até o fim a crença na divindade e em preceitos morais básicos. A dificuldade de observar esses preceitos aguça a loucura. Na terra o homem vive o desregramento de uma unidade perdida, inconsolável órfão de Deus. há um deblaterar insano em terreno hostil. Resta o sentimento permanente de logro. A vida prega uma peça em todo mundo. (MAGALDI, 1992, p. 67)

Esquematicamente, poderíamos assim representar:

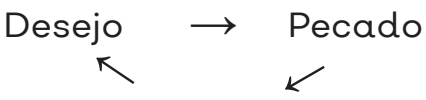

Punição/Redenção 
Nas peças, temos o adultério, $\mathrm{o}$ incesto, a traição, o homossexualismo, a perversidade, o estupro, enfim, o desejo da libido que se projeta no outro o tornando objeto, e não-pessoa, escravizando aquele que deseja e assim desumanizando-o. Nessa relação doentia existe a necessidade de redenção e essa vem pela punição (ou autopunição). Novamente nos valemos da lista de peças elencadas anteriormente para podermos demonstrar essa temática:

Tabela 2

\begin{tabular}{|l|l|}
\hline \multicolumn{1}{|c|}{ Peça } & \multicolumn{1}{|c|}{ Tipo de punição } \\
\hline A mulher sem pecado & $\begin{array}{l}\text { O protagonista se mata } \\
\text { para redimir-se do } \\
\text { sentimento de culpa. }\end{array}$ \\
\hline Vestido de noiva & $\begin{array}{l}\text { A protagonista se atira } \\
\text { em frente a um carro. }\end{array}$ \\
\hline Álbum de família & $\begin{array}{l}\text { Automutilação e morte } \\
\text { como forma de expiação. }\end{array}$ \\
\hline Senhora dos afogados & Suicídio. \\
\hline Dorotéia & Suicídios. \\
\hline A falecida & $\begin{array}{l}\text { Morte como escape } \\
\text { glorioso. }\end{array}$ \\
\hline $\begin{array}{l}\text { Perdoa-me por } \\
\text { me traíres }\end{array}$ & Suicídio imposto. \\
\hline
\end{tabular}

Dessa forma, os personagens se punem ou são punidos por seus objetos (não-seres). Essa punição é consentida ou mesmo requerida na medida em que a trama é na realidade um jogo psicológico que ocorre entre as personagens. Podemos atestar isso quando Sábato Magaldi alega (1992, p. 190): "Em qualquer de suas fases, o teatro rodriguiano importa em violenta catarse". Essa catarse ocorre no seio familiar. Em todas as peças e obras, é na família que ocorre o drama primordial para Nelson. Como na psicanálise freudiana, a família é o berço da primeira tragédia (o complexo de Édipo); para Nelson, a família é o útero das alucinações e da trajetória cristã (desejo, pecado, punição/redenção).

\section{Considerações Finais}

Vivenciar Nelson é enxergar através de um espelho de carne. Nele estão contidas as mazelas de nós mesmos e do mundo disfarcado em sociedade e família. A vida só pode ser entendida a partir de seus desejos e vivenciá-los é um ato religioso. A vida que nos dá prazer, nos mata para que possamos nos redimir dela mesma. O calvário é nossa vida e nossa vida é o próprio ato religioso de desejo, pecado e redenção. Devemos vivenciar o calvário da vida que leva para a morte buscando a redenção. Nelson concordaria com o apóstolo Paulo ao dizer: "miserável homem que eu sou!".

\section{Referências}

ALBUQUERQUE, Maria. Freud x Nélson Rodrigues. Usina de Letras. 2001. Disponível em: $<$ http://www.usinadeletras.com.br>. Acesso em: 6 set. 2002.

CASTRO, Ruy. O Anjo Pornográfico: a vida de Nelson Rodrigues. São Paulo: Companhia das Letras, 1992.

CUNHA, Francisco Carneiro. Nelson Rodrigues, Evangelista. São Paulo: Giordano, 2000.

GUIDARINI, Mário. Nelson Rodrigues: flor de obsessão. Florianópolis: Editora da UFSC, 1990.

JORGE, Marco Antônio Coutinho. Fundamentos da Psicanálise de Freud a Lacan. v. 1. Rio de Janeiro: Jorge Zahar Editor, 2000.

LINS, Ronaldo Lima. O teatro de Nelson Rodrigues: uma realidade em agonia. 2. ed. Rio de Janeiro: Francisco Alves, 1979.

LUCKESI, Elizabeth. O propósito instrutivo dos autos. 2001. Dissertação (Mestrado) - Universidade de Jaú, São Paulo, 2001. Disponível em: <http://cristina.fjaunet.com.br/monografias>. Acesso em: 1 set. 2002.

MAGALDI, Sábato Antônio. Nelson Rodrigues: dramaturgia e encenações. 2. ed. São Paulo: Perspectiva, 1992.

MARTUSCELLO, Carmine. O teatro de Nelson Rodrigues: uma leitura psicanalítica. São Paulo: Siciliano, 1993.

MURPHY, Tom. As Últimas palavras de Nelson Rodrigues: a última entrevista de Nelson Rodrigues. O Estado de S. Paulo, São Paulo, dez. 1980. 
